\title{
The language of intervention: A review of concepts and terminology in wetland ecosystem repair
}

\author{
MC Grenfell ${ }^{1 *}$, WN Ellery ${ }^{1}$, SE Garden ${ }^{1}$, J Dini $^{2}$ and AG van der Valk ${ }^{3}$ \\ ${ }^{1}$ School of Environmental Sciences, University of KwaZulu-Natal, Howard College Campus, Durban 4041, South Africa \\ ${ }^{2}$ Working for Wetlands, South African National Biodiversity Institute, Private Bag X101, Pretoria 0001, South Africa \\ ${ }^{3}$ Ecology, Evolution and Organismal Biology, lowa State University, Ames 50011-1020, lowa, USA
}

\begin{abstract}
As programmes and projects aimed at addressing wetland degradation gain momentum in South Africa, it is critical that related ideas are communicated among and between researchers, practitioners, management agencies, land-owners and the general public in a common language. This paper explores the meaning of 'restoration' and 'rehabilitation'; terms that we suggest are key to understanding and advancing South Africa's efforts to address wetland degradation. In its essence, the paper is a critical review of wetland ecosystem repair concepts and terminology from local and international literature. The major products of the paper are proposed definitions of the terms 'restoration' and 'rehabilitation' in a South African wetland science and management context. Although the terms are often used interchangeably, we argue that their absolute distinction will allow scientists and practitioners to better understand what it is that ecosystem repair interventions aim to achieve. We suggest that the terms be distinguished on the basis of what could be considered their respective ecological starting points, where 'restoration' applies to part of a system or a system in its entirety that has been completely and permanently, but not irreparably altered, and essentially removed from the landscape, and 'rehabilitation' applies to part of a system or a system in its entirety that has not been removed from the landscape through complete and permanent alteration, but is in a degraded state. Thus, 'wetland restoration' is defined as the process of reinstating natural ecological driving forces within part or the whole of a completely and permanently altered wetland to recover former or desired ecosystem structure, function, biotic composition and ecosystem services, while 'wetland rehabilitation' is defined as the process of reinstating natural ecological driving forces within part or the whole of a degraded wetland to recover former or desired ecosystem structure, function, biotic composition and ecosystem services.
\end{abstract}

Keywords: South African wetland science and management, restoration, rehabilitation

\section{Introduction}

Prolonged debate over the definition of terms is commonplace in science, but it draws criticism from practitioners, who may feel that such debate impedes progress on the ground. However, progress in any field of research depends on clarity and consistency in the use of key terms (SWS, 2000), and the intention of research is to generate understanding and ultimately to advance practical efficacy. Furthermore, the definition of key terms has direct implications for what research and practice in a field intend to achieve (setting objectives), and for the way in which what has been achieved will be measured (setting and monitoring performance standards, SWS, 2001, and judging success or failure, Higgs, 2003). As efforts to address wetland degradation gain momentum in South Africa, it is critical that commonly accepted and understood terms be used to describe associated programmes and projects, in order to ensure fruitful communication among and between researchers, practitioners, management agencies, land-owners and the general public. It is our intention with this paper to stimulate debate over the meaning of two terms in particular, 'restoration' and 'rehabilitation', with a critical review of local and international literature as a point of departure. The paper explores the ecological concepts upon which these terms are founded, and the contexts within which they are used.

\footnotetext{
* To whom all correspondence should be addressed.

政 +2772 223 1643; fax: +2731 2601391 ;

e-mail:200268462@ukzn.ac.za

Received 21 July 2006; accepted in revised form 5 October 2006.
}

The phrase 'ecosystem repair' as used in this paper encompasses both 'restoration' and 'rehabilitation', and is used simply to describe, in a broad sense, efforts to address wetland degradation. We neither suggest that this phrase has particular ecological meaning, nor that it be defined and incorporated into the existing terminology. It merely serves as a substitute for 'restoration' and 'rehabilitation' until we have presented our argument for the absolute distinction of the terms in theoretical and practical communication. There is only a slight etymological distinction between the words 'restoration' and 'rehabilitation'. Both derive from Latin, 'restoration' from restaurare; to repair, rebuild or renew, 'rehabilitation' from (re-) habilitare; to make fit (again) or (re-) enable. As a consequence, the words have come to share so similar a core meaning that in most circumstances they could be considered effectively synonymous (Wolvaardt, 2006). While there may be little value in making an absolute distinction between the terms in a common use context, we argue that such distinction is necessary in the context of wetland ecosystem repair.

Ecosystem repair is often touted as an heuristic exercise, or a test of ecological understanding (Jordan et al., 1987). In repairing degraded wetlands, scientists and practitioners are afforded an opportunity to both test and further their understanding of how wetlands work. This is only feasible if scientists and practitioners carefully consider what interventions aim to achieve. Using the terms 'restoration' and 'rehabilitation' interchangeably is of no heuristic value to the science or practice of wetland ecosystem repair. Thus, we propose that these terms be used, at least in South Africa, in a more constructive manner: 


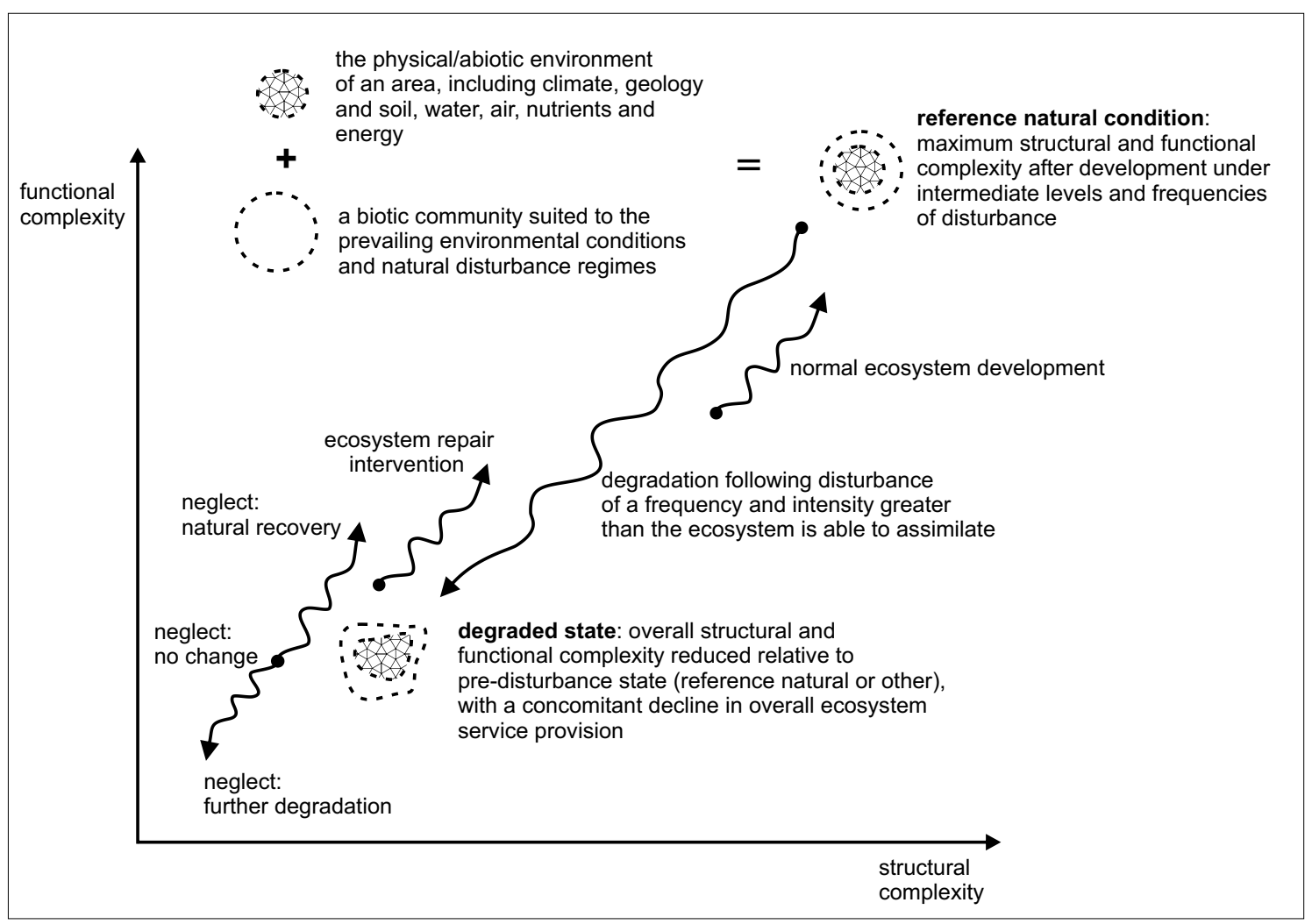

Figure 1

A conceptual model depicting pathways of ecosystem development (adapted from Magnuson et al., 1980 and Bradshaw, 1984; 1987).

Key to Figure 1

Ecosystem structure: the physical characteristics of an ecosystem, what the system is 'like'.

Ecosystem function: the physical processes operative within an ecosystem (Hobbs and Norton, 1996), how the system 'works'. Ecosystem services: the benefits (e.g., flood attenuation, cleaner water) or products (e.g., fish, furs, timber) of an ecosystem that are of value to society (Woodward and Wiu, 2001; MEA, 2005).

- To carefully consider, describe and distinguish intentions of wetland ecosystem repair

- As a first step to carefully prioritising scarce resources across a range of wetlands in various states of degradation, and planning approaches to addressing degradation

The many attempts made previously to distinguish absolutely between the terms 'restoration' and 'rehabilitation' have achieved variable success. We suggest why this is the case, and propose a point about which the terms may be absolutely distinguished.

\section{A conceptual framework for wetland ecosystem repair terminology}

An 'ecosystem' comprises the physical or abiotic environment of an area, including its climate, geology and soil, water, air, nutrients and energy, together with a biotic community suited to the prevailing environmental conditions and natural disturbance regimes. Such a system may be in various states, depending upon the frequency and intensity of disturbances by, for example, fire, herbivory or flooding, to which it is exposed. Systems within which such disturbance is sufficiently frequent or of sufficiently low intensity to place organisms under selective pressure will maximise both structural and functional complexity. This is captured in the intermediate disturbance hypothesis, which states that both structural and functional attributes of an ecosystem reach a maximum at intermediate levels and frequencies of disturbance (Horn, 1975; Connell, 1978). A system that experiences intermediate natural disturbance and has developed maximum structural and functional complexity for the given set of abiotic environmental conditions prevalent is considered to be in a 'reference natural state' (Fig. 1).

Associated with this state is a suite of ecosystem services, such as flood attenuation and water quality enhancement, which are of perceived value to human society. While a less-than-reference-natural ecosystem state may provide certain ecosystem services more effectively than the reference natural state (Hruby, 2001), an ecosystem in a more natural state is assumed to provide an overall suite of associated ecosystem services more effectively than it would in a less natural state. Anthropogenic disturbance of natural systems occurs at frequencies and intensities that organisms and natural mechanisms of recovery are often unable to assimilate. Thus, a common result of anthropogenic disturbance, or conversion of an ecosystem for anthropogenic uses, is a reduction in overall structural and functional complexity (Bradshaw, 1987), with a concomitant decline in overall ecosystem service provision (Fig. 1). The 'reference natural state' was chosen as the starting point in Fig. 1 simply for illustrative purposes. In reality, we seldom know the condition of an ecosystem prior to modern anthropogenic impacts, and it may have been in a less-than-reference-natural state prior to anthropogenic disturbance. It is therefore more appropriate to assess reductions in ecosystem complexity and service pro- 
vision associated with anthropogenic disturbance relative to the state of the system prior to such disturbance. It must also be acknowledged that natural disturbances may have a similar effect as anthropogenic disturbances.

A number of difficulties arise in any attempt to conceptualise ecological characteristics and processes in simple twodimensional models, mainly due to the complex interplay of physical, relative and relational space concepts operative within ecological theory. For example, although climax species may not coexist with pioneer species in the same physical space at the same time, the occurrence of certain climax species at a site often depends upon the prior occurrence of certain pioneer species at the site. Thus, in this example, although the pioneer species are not related to the climax species in physical, quantifiable space, they are strongly associated in relational space. It is not easy to illustrate these spatial relations on paper. The following points are therefore worth noting:

- Ecosystems should be conceived as dynamic systems, rather than static entities, characterised by spatially and temporally varying abiotic forces that interact with biotic processes to create a continually changing landscape and a diverse biotic community (De Angelis and White, 1994). There is a largely economic and engineering-led misconception that 'restoration' or 'rehabilitation' are ecological products of our interventions, static endpoints of recipe-like processes (Kusler and Kentula, 1990), rather than processes in their own right. In repairing an ecosystem we do not aspire to create an end, but rather we aspire to provide the system an opportunity for a new beginning (by resetting the 'ecological clock', Jordan et al., 1987).

- The wavy lines in Fig. 1 emphasize that ecosystem development follows a 'bumpy' path and thus outcomes are difficult to predict (Magnuson et al., 1980). Furthermore, although ecosystem development, degradation and repair are depicted in Fig. 1 as proceeding along parallel paths but in opposite directions, in reality development, degradation and repair are more complex, potentially involving many paths of change in ecosystem structure and function (Zedler, 2000). Figure 1 is thus a conceptual simplification of this more complex reality.

Faced with a degraded ecosystem, society may decide to do very little or nothing at all; that is, to neglect the ecosystem (Bradshaw, 1987). It is unlikely that an ecosystem will remain indiscernibly changed for very long - the dynamic nature of biotic/abiotic interaction predisposes ecosystems to change. Thus, more likely outcomes of neglect are further degradation, or recovery by natural processes, such as succession, to some semblance or dissemblance of the ecosystem's former self. It is possible that recovery by natural processes will improve an ecosystem's biotic composition, structure, functions and service provision to a level that is comparable with that which intervention would aim to achieve. However, processes of natural recovery may require decades to yield desired ecosystem characteristics and services (Mentis and Ellery, 1994). Thus, society may decide to intervene in order to improve ecosystem characteristics and recover some or the entire suite of ecosystem services lost following degradation over a shorter timeframe. In a general overarching sense then, the purpose of ecosystem repair intervention is to aid the recovery of an ecosystem (SER, 2004) to some former, useful or desired state.

It is apparent from the above discussion that the discourse that motivates ecosystem repair intervention in ecosystems is one framed in the recovery of lost ecosystem characteristics and services. These characteristics and services range from the quantifiable (measurement of species diversity), and the crudely quantifiable (measurement of wetland flood attenuation effectiveness using a tool such as WET-Ecoservices, Kote et al., 2005), to the wholly normative (describing the cultural value of a wetland to a particular people or community). Setting objectives and judging success in terms of improvements to ecosystem health; the similarity (in terms of ecosystem characteristics and processes) of an ecosystem to a defined natural state, has been little explored. This is perhaps because the ecosystem health metaphor, although widely used in formulating public policy, is normative and has no precise ecological meaning (Lackey, 2001; Davis and Slobodkin, 2004). If it is to be ecologically meaningful and useful, then clearly defined and quantifiable attributes of ecosystem structure, function or composition need to be specified as suitable indicators of health. South African wetland ecologists have attempted to account for this with the development of a tool (WET-Health) for the assessment of wetland health that has already found application in planning and assessing the effectiveness of wetland ecosystem repair interventions (MacFarlane, 2006).

\section{A critical review of 'restoration' and 'rehabilitation' definitions}

\section{Current term usage}

The terms 'restoration' and 'rehabilitation' have been used interchangeably in the literature (as in Mitsch and Gosselink, 1993; Streever, 1999 and Cooke and Johnson, 2002). Where authors have attempted to distinguish between the terms, this has generally been based on what were considered to be the terms' respective goal endpoints or the degree of ambition (Van Diggelan et al., 2001; Higgs, 2003) of an intervention (Table 1).

By this distinction, restoration generally refers to the attainment of former (prior to anthropogenic disturbance) ecosystem structure, function and/or state, while rehabilitation refers to progression towards the attainment of former ecosystem structure, function and/or state (attainment of a state that is as near to the former as resources or local conditions allow), or the attainment of ecosystem structure, function and/or state that differs from the former (attainment of some desired state). In reality, the prediction of outcomes or endpoints of ecosystem repair interventions is considered either nearly impossible to achieve (Zedler, 2000), or an inappropriate venture to begin with (Allen et al., 2003). In order to predict the outcomes of system process-response interactions, our understanding of a system must be such that we are able to gain control of it, that we are able to take at least as many distinct actions as the system is able to exhibit (Ashby, 1964; Chorley and Kennedy, 1971). Natural systems are prone to chaotic behaviour and are inherently difficult to control, making prediction of outcomes in ecosystem repair unreliable.

Where the use of one term (either 'restoration' or 'rehabilitation') has been favoured to the exclusion of the other, definitions display considerable overlap in meaning (Tables 2 and 3). The reason for this overlap in meaning is that both terms are not merely associated with commensurate paradigms, but in fact share a common ethic and paradigm (the imitation of nature, the reinstatement of systems that are similar to their natural counterparts in critical ways and therefore act the same, Jordan et al., 1987). Consequently, these terms have often been used as synonyms (Higgs, 2003). 


\begin{tabular}{|l|l|l|}
\hline \multicolumn{3}{|c|}{ Examples of goal endpoints of 'restoration' and 'rehabilitation' } \\
\hline Source & Goal endpoint of restoration & Goal endpoint of rehabilitation \\
\hline Bradshaw (1984) & $\begin{array}{l}\text { Original ecosystem in all its structural and func- } \\
\text { tional aspects }\end{array}$ & $\begin{array}{l}\text { Progression towards reinstatement of original } \\
\text { ecosystem }\end{array}$ \\
\hline Lewis (1990) & Previously existing natural or altered condition & $\begin{array}{l}\text { System that differs from original but deemed to be } \\
\text { better for overall ecology of area }\end{array}$ \\
\hline Rutherfurd et al. (2000) & $\begin{array}{l}\text { General structure, function and dynamic, but self- } \\
\text { sustaining behaviour of pre-disturbance ecosystem }\end{array}$ & Progression towards restoration \\
\hline $\begin{array}{l}\text { McCarty and Zedler } \\
\text { (2002) }\end{array}$ & $\begin{array}{l}\text { System with level of ecological integrity that } \\
\text { existed prior to human disturbance }\end{array}$ & $\begin{array}{l}\text { Where past conditions cannot be recreated, an } \\
\text { alternative ecosystem to that which existed prior } \\
\text { to human disturbance }\end{array}$ \\
\hline Higgs (2003) & Re-establishing the original or historic ecosystem & Establishing an acceptable ecosystem \\
\hline $\begin{array}{l}\text { Van Diggelen et al. } \\
\text { (2001), Van Andel and } \\
\text { Aronson (2006) }\end{array}$ & $\begin{array}{l}\text { Previous situation or self-sustaining target, includ- } \\
\text { ing former functions, characteristic species and } \\
\text { communities }\end{array}$ & $\begin{array}{l}\text { Restoration or certain ecosystem functions, make } \\
\text { parts of the landscape more natural but do not } \\
\text { increase biodiversity in whole landscape }\end{array}$ \\
\hline
\end{tabular}

\begin{tabular}{|l|l|}
\hline \multicolumn{2}{|c|}{ Definitions of 'restoration' from works that exclude or disregard the term 'rehabilitation' } \\
\hline Source & Summary of definition of restoration \\
\hline SWS (2000) & $\begin{array}{l}\text { Actions taken that result in re-establishment of ecological processes, functions and biotic/abiotic linkages } \\
\text { and lead to persistent, resilient system integrated within its landscape }\end{array}$ \\
\hline Olin et al. (2000) & $\begin{array}{l}\text { Establishment or re-establishment of conditions conducive to development of viable wetland } \\
\text { ecosystem }\end{array}$ \\
\hline Bardsley et al. (2001) & Restitution to some former or desired state \\
\hline & \\
\hline
\end{tabular}

\begin{tabular}{|l|l|}
\hline \multicolumn{2}{|c|}{ Definitions of 'rehabilitation' from works that exclude or disregard the term 'restoration' } \\
\hline Source & Summary of definition of rehabilitation \\
\hline Mentis and Ellery (1994) & $\begin{array}{l}\text { Restoring a natural dynamic to ecological communities comprised of strongly or weakly interacting } \\
\text { species }\end{array}$ \\
\hline Collins (2000) & Returning a wetland to a more natural state \\
\hline Kotze et al. (2001) & $\begin{array}{l}\text { Reinstating ecological driving forces of a system so that it will return to a state in which it is of value } \\
\text { to society }\end{array}$ \\
\hline
\end{tabular}

\section{Proposed future term usage}

Thus, distinguishing the terms on the basis of their respective goal endpoints or on the basis of what each intends to achieve, is of little value, either for heuristic or applied purposes. We suggest that the terms be distinguished on the basis of what could be considered their respective ecological starting points (Fig. 2). The term 'restoration' according to the suggested framework (Fig. 2) would therefore be most appropriately applied to systems or parts of systems that have essentially been lost in their entirety through complete and permanent, but not irreparable, alteration of ecosystem structure, function, biotic composition and associated ecosystem services (Fig. 3). Obviously if changes are deemed to be irreparable, one would need to carefully consider the motivation for intervening at all. The term 'rehabilitation' would be most appropriately applied to systems or parts of systems that have not been removed from the landscape through complete and permanent alteration but are in a degraded state, having lost a degree of ecosystem structure, function, biotic composition and associated ecosystem services.

In practice, determining whether or not a system has been completely and permanently altered may be a difficult exercise. We advocate the use of a tool such as WET-Health which provides an indication of the similarity of a wetland to a former natural state in terms of hydrology (Module 1), geomorphology (Module 2), and vegetation (Module 3). If a wetland being considered for intervention scores in the lowest health category for hydrology or geomorphology (the fundamental abiotic driving forces which wetland ecosystem repair interventions aim to reinstate), the proposed intervention would be considered restoration rather than rehabilitation. The description corresponding to the lowest health category in WET-Health (category F) is: 'Modifications have reached a critical level and the ecosystem processes have been modified completely with an almost complete loss of natural habitat and biota'.

Defining terms used in restoration ecology in relation to starting conditions was previously proposed by Lewis (1990). He distinguished between restoration (returning a disturbed or totally altered wetland to a previously existing natural or altered condition), rehabilitation (converting a wetland that had been filled-in to a wetland that differs from the previously existing wetland), creation (converting a non-wetland to a wetland), and enhancement (increasing one or more functions of an existing wetland often with an accompanying loss or alteration of other wetland functions). Lewis' definition of restoration is largely consistent with our proposed definition. His definition of rehabilitation, however, differs significantly from ours. A rehabilitation project for Lewis implies a different endpoint than that of a restoration project at the same site. As we define restoration and 


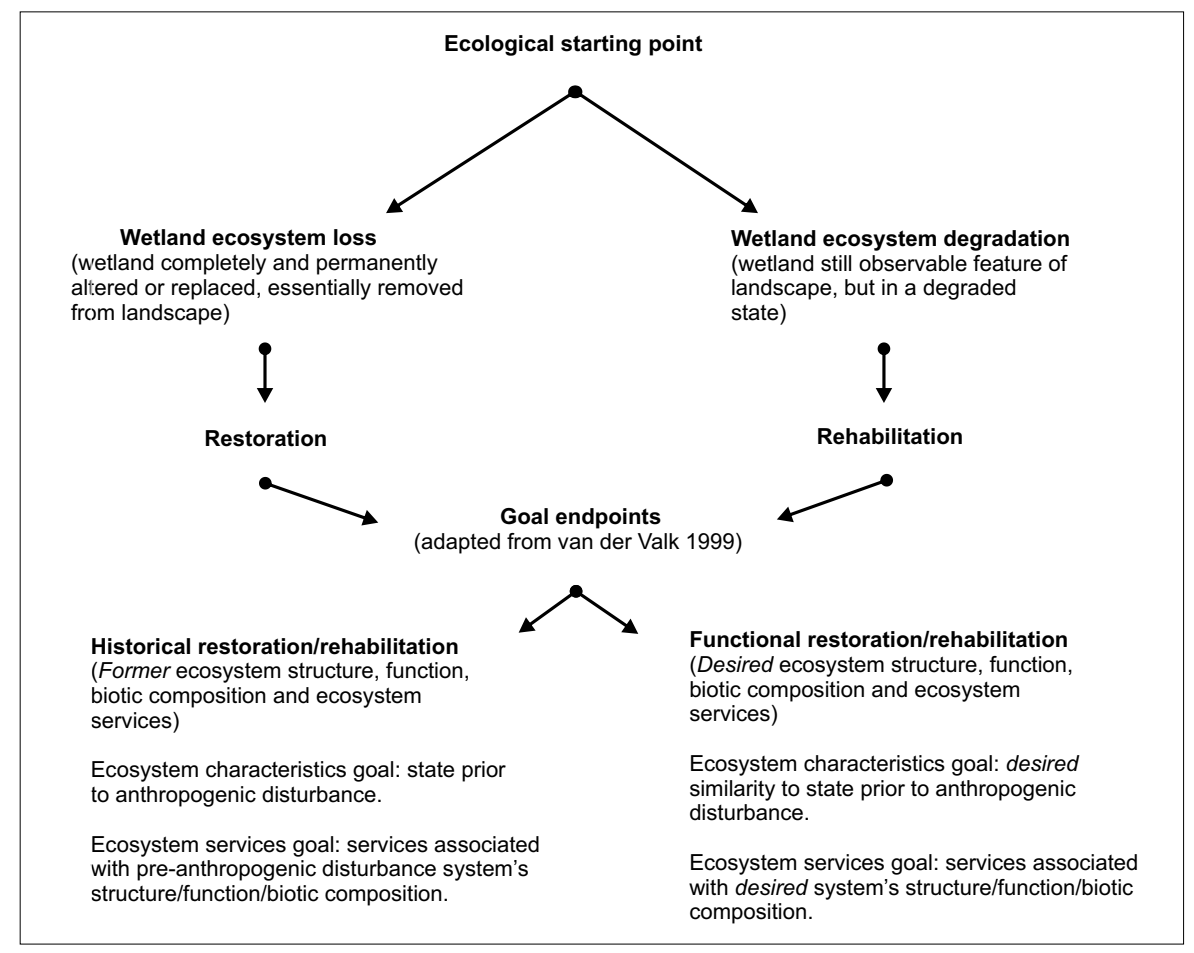

Figure 2

A framework for distinguishing the terms 'restoration' and 'rehabilitation'

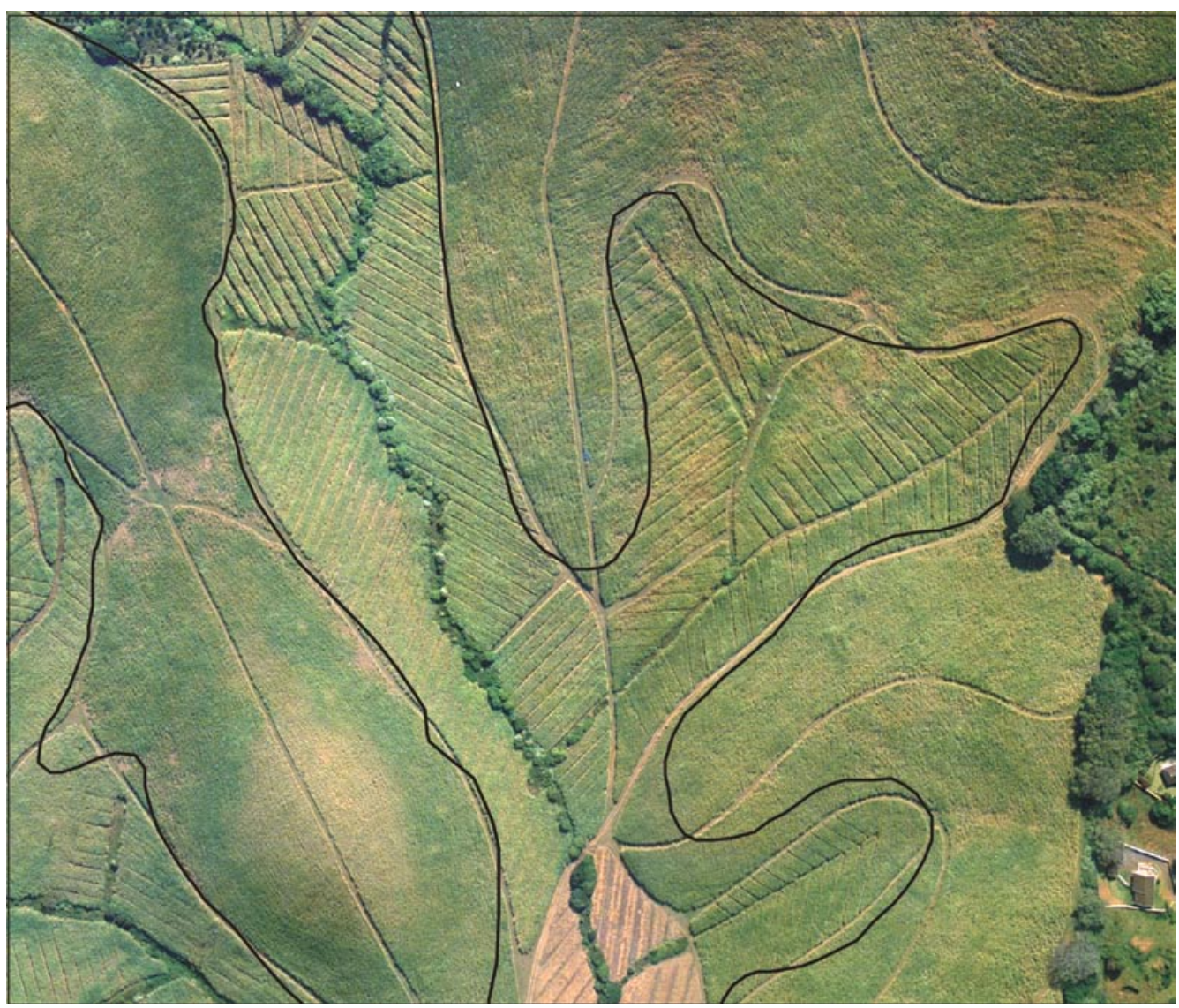

Figure 3

One of South Africa's 'lost' wetlands, the natural hydrological regime completely and permanently (but not necessarily irreparably) altered by an effective 'herringbone' network of drains, and natural hydrophytic vegetation replaced by sugarcane (wetland delineation detail undertaken by Land Resources International (Pty) Ltd., on behalf of Moreland Developments (Pty) Ltd.). 
rehabilitation, assuming similar project goals, their endpoints would be the same or at least similar (Fig. 2). Enhancement as defined by Lewis is not equivalent to our concept of rehabilitation, but there is some overlap. Whereas enhancement for Lewis does not presuppose that the wetland has been degraded or damaged in any way, this is explicit in our definition of rehabilitation. For Lewis, and enhancement project might involve raising the water level of an existing pristine wetland to improve this wetland as waterfowl habitat.

Having distinguished the meaning of the two terms on the basis of ecological starting point, our proposed framework suggests that ecosystem repair intervention objectives may be guided by one of two overarching purposes or goal endpoints (Fig 2): to reinstate fundamental ecological driving forces and provide an environment conducive to the recovery of former (pre-human disturbance) ecosystem structure, function, biotic composition and associated ecosystem services (historical restoration/rehabilitation, adapted from van der Valk 1999), or to reinstate fundamental ecological driving forces and provide an environment conducive to the recovery of desired ecosystem structure, function, biotic composition and associated ecosystem services (functional restoration/rehabilitation, adapted from van der Valk 1999). The latter acknowledges that reinstating a past state (historical restoration/rehabilitation) may neither yield returns in ecosystem structure, function, biotic composition and/or the delivery of ecosystem services that are desirable to society, nor be achievable with available resources, nor be appropriate for present environmental conditions (McCarty and Zedler (2002) suggest that global environmental changes, notably climate change, may render environmental conditions inappropriate for the communities of recent history). This distinction also acknowledges that not all wetland restoration and rehabilitation projects aim to re-establish historic wetlands; many aim to obtain specific societal benefits such as flood attenuation or cleaner water. All rehabilitation/restoration interventions should be integrated into local landscapes and ideally should be designed to require minimal maintenance (SWS, 2000).

\section{Conflicting contexts}

When Aldo Leopold (considered by many to be the father of 'restoration ecology') began restoring tall-grass prairie in Wisconsin in 1935, he did so on land that had been converted (transformed such that it was completely and permanently altered) from its natural state for agricultural purposes (Jordan et al., 1987). Similarly, the restoration of prairie pothole wetlands in the north-eastern United States involved reinstating wetland systems that had been removed from the landscape in their entirety and replaced by farmland over a century before through extensive networks of tile lines and drainage ditches (Galatowitsch and Van der Valk, 1998). Over much of Europe, restoration interventions target lands that have been completely and permanently altered from their natural condition (Hodge and McNally, 2000; Van Andel and Aronson, 2006). It is in these, often highly modified settings that 'restoration ecology' has its roots.

In North America and Europe, three different normative views are used to justify the repair of damaged ecosystems: the wilderness, the arcadian, and the functional (Swart et al., 2001). The wilderness view assumes that ecosystems are self-regulating and there should be no or very little human influence on their development and management. The arcadian view is more prevalent in Europe and other areas where most of the landscape has been transformed for centuries or millennia into semi-natural or cultural ecosystems like farms. The arcadian view stresses cooperation between people and nature and the preservation and repair of human-made ecosystems. Adherents of the functional view stress that all the ecosystems in a landscape ideally should have some economic value, if not to individuals then at least to society. The functional view tends to be strongest in the environmental engineering community. In various countries, large- and small-scale wetland ecosystem repair projects have been initiated by government agencies and private groups in response to the increasingly widespread adoption of one or more of these views. In North America and Europe, the wilderness view is the dominant valuation paradigm with pristine, self-regulating ecosystems being the ideal outcome.

In South Africa, a combination of arcadian and functional views has provided the primary motivation for wetland ecosystem repair projects. In order to obtain the desired functional results and thus future funding, scarce resources and limited expertise here dictate careful prioritisation in selecting which wetlands should be targeted for repair. Current thought in this regard favours attending to systems that are in good condition (that are 'saveable') before those that are in poor condition (Rutherfurd et al., 2000). It is therefore unlikely that wetland systems in South Africa that have been completely and permanently altered or removed from the landscape will be the target of WFWetlands' investment, unless they have particular strategic or symbolic value. In other words, rehabilitation projects should be favoured over restoration projects.

\section{Conclusion}

Repairing damaged ecosystems is a venerable theoretical and practical undertaking within the ecological and environmental sciences. Wetland ecosystem repair interventions should reflect the eclectic nature of the wetland science research corpus, and should strive to both feed and feed off this body of research to enhance the efficacy of intervention. The attempt made in this paper to distinguish more absolutely the meaning of the terms 'restoration' and 'rehabilitation' was motivated by the view that a clear distinction of terms is preferable to their interchangeable use, and would have the following advantages:

- The meaning of individual terms may be used to carefully consider, describe and distinguish intentions of wetland ecosystem repair

- 'Restoration' according to the definition proposed in this paper, implies a higher demand in intervention effort and resources than 'rehabilitation'. Thus, determining whether a wetland requires restoration or rehabilitation is a useful first step to carefully prioritising scarce resources across a range of wetlands in various states of degradation, and planning approaches to addressing degradation.

The paper demonstrated that distinguishing the terms on the basis of their respective goal endpoints or on the basis of what each intends to achieve, is of little value, either for heuristic or applied purposes. Thus, wetland 'restoration' and 'rehabilitation' in South Africa should be distinguished on the basis of what could be considered their respective ecological starting points, where 'restoration' applies to part of a system or a system in its entirety that has been completely and permanently, but not irreparably altered, and essentially removed from the landscape, and 'rehabilitation' applies to part of a system or a system in its entirety that has not been removed from the landscape through complete and permanent alteration, but is in a degraded state. In this context, 'wetland restoration' is defined as the process of reinstating natural ecological driving forces within part or 
the whole of a completely and permanently altered wetland to recover former or desired ecosystem structure, function, biotic composition and/or ecosystem services. 'Wetland rehabilitation' encompasses most of the interventions implemented by WFWetlands, and is defined as the process of reinstating natural ecological driving forces within part or the whole of a degraded wetland to recover former or desired ecosystem structure, function, biotic composition and/or ecosystem services. WET-Health (Mcfarlane et al., 2006) will allow practical on-the-ground distinction between wetlands requiring rehabilitation and those requiring restoration.

In writing this paper we purposefully steered clear of definitions from South African policy and law, opting instead to draw meaning from academic literature and thus stimulate debate that we hope will permeate policy and legal arenas. Although selected concepts related to ecosystem repair are referred to in various South African Acts (ECA 73 of 1989, NEMA 107 of 1998, NWA 36 of 1998, CARA 43 of 1983, NEM: BA 10 of 2004), the meaning of the terms 'restoration' and 'rehabilitation' is only loosely explained in our legislation, if at all. None of our Acts include explicit definitions of the terms, and the most one is able to gain in understanding what the terms mean in the context of wetland ecology from a legal or policy perspective is that 'rehabilitation measures are part of water resource protection' (NWA 36 of 1998). Definitions for the terms are included in the White Paper on the Conservation and Sustainable use of South Africa's Biological Diversity (Notice 1095 of 1997), in which the terms are distinguished on the basis of endpoint. In this paper, rehabilitation means: 'to return a degraded ecosystem or population to an un-degraded condition and to productive use', while restoration means: 'to return a degraded ecosystem or population to its original condition'. These definitions were not carried to the National Environmental Management: Biodiversity Act 10 of 2004, from which the terms have been excluded. Ecosystem repair projects in South Africa are increasingly attracting substantial public funding. It would thus be opportune for South African policy and law to adopt a terminology that is consistent with and well founded in the science and practice of ecosystem repair.

\section{Acknowledgements}

This work is a product of the South African National Biodiversity Institute/Water Research Commission research project on wetland rehabilitation, jointly funded by these organisations. Comments from the anonymous referees proved invaluable to the final revision of the paper, as did a constructive and thoughtprovoking review by the Executive Director and Editor in Chief, Dictionary Unit for SA English, Jill Wolvaardt.

\section{References}

ALLEN TFH, GIAMPIETRO M and LITTLE AM (2003) Distinguishing ecological engineering from environmental engineering. Ecol. Eng. 20 389-407.

ASHBY WR (1964) An Introduction to Cybernetics. Methuen, London. $295 \mathrm{pp}$.

BARDSLEY L, GILES N and CROFTS A (2001) Wetland Restoration Manual. The Wildlife Trusts, Nottinghamshire.

BRADSHAW AD (1984) Ecological principles and land reclamation practice. Lands. Plan. 11 35-48.

BRADSHAW AD (1987) The reclamation of derelict land and the eco logy of ecosystems. In: Jordan WR, Gilpin ME and Aber JD (eds.) Restoration Ecology: A Synthetic Approach to Ecological Research. Cambridge University Press, Cambridge. 53-74.
CHORLEY RJ and KENNEDY BA (1971) Physical Geography: A Systems Approach. Prentice-Hall, London. 370 pp.

COLLINS C (2000) Wetland Rehabilitation: Getting Started. Wetland Care Australia, Ocean Watch and NSW State Wetland Action Group. 26 pp.

CONNELL JH (1978) Diversity in tropical rainforests and coral reefs. Sci. 199 1302-1310.

COOKE JA and JOHNSON MS (2002) Ecological restoration of land with particular reference to the mining of metals and industrial minerals: a review of theory and practice. Environ. Rev. 10 41-71.

DAVIS MA and SLOBODKIN LB (2004) The science and values of restoration ecology. Restor. Ecol. 12 1-3.

DEANGELIS DL and WHITE PS (1994) Ecosystems as products of spatially and temporally varying driving forces, ecological processes, and landscapes: A theoretical perspective. In: Davis SM and Ogden JC (eds.) Everglades: The Ecosystem and its Restoration. St. Lucie Press, Florida. 9-27.

GALTOWITSCH SM and VAN DER VALK AG (1998) Restoring Prairie Wetlands. An Ecological Approach. Iowa State University Press, Ames, Iowa. $246 \mathrm{pp}$.

HIGGS E (2003) Nature by Design: People, Natural Processes, and Ecological Restoration. MIT Press, Cambridge, Massachusetts. $341 \mathrm{pp}$.

HOBBS RJ and NORTON DA (1996) Towards a conceptual framework for restoration ecology. Restor. Ecol. 4 93-110.

HODGE I and MCNALLY S (2000) Wetland restoration, collective action and the role of water management institutions. Ecol. Econ. 35 107-118.

HORN HS (1975) Markovian processes of forest succession. In: Cody ML and Diamond JM (eds.) Ecology and Evolution of Communities. Belknap, Cambridge, MA. 196-213.

HRUBY T (2001) Testing the basic assumption of the hydrogeomorphic approach to assessing wetland functions. Environ. Manage. 27 749761.

JORDAN WR (III), GILPIN ME and ABER JD (1987) Restoration Ecology: ecological restoration as a technique for basic research. In: JordanWR (III), Gilpin ME and Aber JD (eds.) Restoration Ecology. A Synthetic Approach to Ecological Research. Cambridge University Press, Cambridge. 3-21.

KOTZE DC, ELLERY WN, BECKEDAHL H, WINSTANLEY T, MARNEWECK G, BATCHELOR A, COLLINS N, RUSSELL W, WALTERS D, BRAACK M and COWDEN C (2001) Wetland Rehabilitation Manual. Wetland Rehabilitation CD-ROM, Mondi Wetlands Project.

KUSLER JA and KENTULA ME (eds.) (1990) Wetland Creation and Restoration: The Status of the Science. Island Press, Washington, DC. $594 \mathrm{pp}$.

LACKEY RT (2001) Values, policy, and ecosystem health. BioSci. 51 437-443.

LEWIS RR (1990) Wetlands restoration/creation/enhancement terminology: suggestions for standardisation. In: Kusler, JA and Kentula, ME (eds.) Wetland Creation and Restoration: The Status of the Science, Island Press, Washington, DC. 594 pp.

MAGNUSON JJ, REGIER HA, CHRISTIE WJ and SONZOGNI WC (1980) To rehabilitate and restore Great Lakes ecosystems. In: Cairns (Jr.) J (ed.) The Recovery Process in Damaged Ecosystems, Ann Arbor Science, Michigan. 95-112.

MACFARLANE DM (2006) Personal communication. SHEQ Manager, Sappi Forests (Pty) Ltd.

McCARTY JP and ZEDLER JB (2002) Restoration, Ecosystem. In: Munn, T (ed.) Encyclopedia of Global Environmental Change (Vol. 2). Wiley, Chichester. 532-539.

MENTIS MT and ELLERY WN (1994) Post-mining rehabilitation of dunes on the north-east coast of South Africa. S. Afr. J. Sci. 90 69-74.

MILLENNIUM ECOSYSTEM ASSESSMENT (2005) Ecosystems and Human Well-being: Synthesis. Island Press, Washington, DC. 155 pp.

MITSCH WJ and GOSSELINK JG (1993) Wetlands ( $2^{\text {nd }}$ edn.) Van Nostrand Reinhold, New York. 722 pp.

OLIN TJ, FISHENICH JC, PALERMO MR and HAYES DF (2000) 
Wetlands Engineering Handbook. US Army Corps of Engineers, Wetlands Research Programme, Washington DC. 719pp.

RUTHERFURD ID, JEIRE K and MARSH N (2000) A Rehabilitation Manual for Australian Streams (Vol. 1). Joint publication by the Cooperative Research Centre for Catchment Hydrology and Land and Water Resources Research and Development Corporation, Canberra (now Land and Water, Australia).

SER (Society for Ecological Restoration International Science and Policy Working Group) (2004) The SER International Primer on Ecological Restoration. Available online at http://www.ser.org Society for Ecological Restoration International, Tucson, Arizona. (Accessed on 12/4/2006).

SWS (Society of Wetland Scientists) (2000) Position Paper on the Definition of Wetland Restoration. Available online at http://Www.sws. org/wetlandconcerns (Accessed on 12/4/2006). SWS Wetlands Concerns Committee.

SWS (Society of Wetland Scientists) (2001) Position Paper on Performance Standards for Wetland Restoration and Creation. Available online at http://www.sws.org/wetlandconcerns (Accessed on 12/4/2006). SWS Wetlands Concerns Committee.
STREEVER WJ (ed.) (1999) An International Perspective on Wetland Rehabilitation. Kluwer Academic Publishers, the Netherlands. 338 pp. SWART JAA, VAN DER WINDT HJ and KEULARTZ J (2001) Valuation of nature in conservation and restoration. Rest. Ecol. 9 230-238.

VAN ANDEL J and ARONSON J (eds.) (2006) Restoration Ecology. The New Frontier. Blackwell Science, Oxford. 319 pp.

VAN DER VALK AG (1999) Succession theory and restoration of wetland vegetation. In: McComb AJ and Davis J (eds.) Wetlands for the Future. Gleneagles Publishing, Adelaide. 657-667.

VAN DIGGELEN R, GROOTJANS AP and HARRIS JA (2001) Ecological restoration: state of the art or state of the science. Rest. Ecol. 9 115-118.

WOLVAARDT J (2006) Personal communication. Executive Director and Editor in Chief, Dictionary Unit for South African English, Rhodes University, Grahamstown. September 2006.

WOODWARD RT and WIU Y-S (2001) The economic value of wetland services: A meta-analysis. Ecol. Econ. 37 257-270.

ZEDLER JB (2000) Progress in wetland restoration ecology. Tree 15 402-407. 